\title{
Identifying Evidence-Based Educational Practices: Which Research Designs Provide Findings That Can Influence Social Change?
}

\author{
Barbara R. Schirmer \\ Walden University \\ Alison S. Lockman \\ Walden University \\ Todd N. Schirmer \\ Napa State Hospital
}

\begin{abstract}
We conducted this conceptual study to determine if the Institute of Education Sciences/National Science Foundation pipeline of evidence guidelines could be applied as a protocol that researchers could follow in establishing evidence of effective instructional practices. To do this, we compared these guidelines, new drug development process, and our own research on major methodological designs and found that they show remarkable consistency in the process by which types of studies intended to answer different research questions build a body of evidence for practice, whether that practice is in the instructional environment or health care environment. However, none of the protocols offers a constellation of studies at each stage that would be essential for movement to the next stage or the indicators of quality for each type of study. The goal of this effort is to develop consensus in the educational research community about a pipeline of evidence protocol that provides educators with confidence that the instructional practices they employ have a high likelihood of success and will enable a positive impact on the student's learning and, in the broader context, the student's ability to contribute to society.
\end{abstract}

Keyw ords: research designs, methodology, evidence-based practices

\section{Introduction}

In the United States, the national debate on the meaning and value of scientific research has involved a spectrum of views ranging from those of public policymakers who pass legislation that is not informed by educational research to scholars who describe educational research as a complex set of methodologies necessary to match to complex research questions. No Child Left Behind (reauthorization of the Elementary and Secondary Education Act of 2001 and the more recent Every Student Succeeds Act of 2015); the passage of the Education Sciences Reform Act of 2002, which established the Institute of Education Sciences (IES) within the U.S. Department of Education; and subsequent legislation have been catalysts in this debate.

Given concerns about the quality of research in education and questions about what constitutes evidence for informing instructional practice, several preeminent professional organizations developed standards for quality research including the American Educational Research Association (2006), American Association of Colleges for Teacher Education (2006), Council for Exceptional 
Children (2005, 2014), and Division 16 of the American Psychological Association and the Society for the Study of School Psychology (2003). In spite of considerable discussion in the literature, at conferences and meetings, and in online venues about evidence-based practices, no consensus has emerged about what constitutes sufficient evidence to identify an educational practice as researchbased, with proposed algorithms involving dissimilar configurations of quantities, qualities, and types of research (e.g., Cooper, 2010; Gersten et al., 2005; Kazdin, 2011; What Works Clearinghouse, 2010).

In August of 2013, the IES and the National Science Foundation (NSF) issued common guidelines for education research and development. Their purpose was "to identify the spectrum of study types that contribute to development and testing of interventions and strategies, and to specify expectations for the contributions of each type of study" (IES \& NSF, 2013, p. 8). The report describes relevant educational research as forming a pipeline of evidence that contributes to the accumulation of empirical evidence and development of theoretical models. This is the newest entry in the debate about evidence-based practices in education, and given that these federal agencies distribute millions of dollars in grants to support research that meets their defined criteria of quality research and promising evidence for practice, their guidelines will likely be highly influential among educational researchers.

It is timely for those engaged in educational research to determine if there is a common denominator protocol by which the use of particular methodological designs in a line of research inquiry provides evidence for each successive step in the process of bringing any given instructional intervention into practice. If schools are agents of social change, as Dewey (1937) proposed almost a century ago, then it is crucial for students to be immersed in educational practices that enable them to be knowledgeable about the global society in which they live, think critically about their environment, communicate effectively, and feel empowered to take action that will affect social change. We suggest that effective instructional practices are essential for achieving these learning outcomes.

It is clear that identification of evidence-based practices should not involve the identical processes that researchers and educators have historically employed to identify "best practices." Best practices emerged from a personal perspective on the value of a particular instructional practice based on experience, predisposition, and interpretations of a particular body of literature. There has never been consensus around criteria for what constitutes evidence for best practices. Alternatively, evidence-based practices are intended to emerge from verifiable, scientific evidence for effectiveness. The research community may argue about what kinds of research are scientific but the intent is to seek convergence on criteria rather than to continue relying on disparate notions on the nature of scientific evidence. Establishing practices as evidence based should not only provide teachers and other stakeholders with a more objective and complete indication of which practices can be considered evidence based, but may also begin to change perceptions regarding the trustworthiness and relevance of educational research.

The purpose of this conceptual piece is to determine whether the recent report issued jointly by the IES and NSF provides a reasonable protocol that explains the differential role of methodological designs in lines of research inquiry that culminate in evidence-based instructional practices. 


\section{Mode of Inquiry and Data Sources}

We began by identifying three premises that would serve to guide the establishment of a protocol.

1. We took the position that no one methodological design is superior to any other design. Each serves a different purpose within lines of research that lead to greater understanding of learning and for identifying practices that are increasingly more effective in teaching. Although some researchers might argue that the primary purpose of research is to pursue truth rather than to identify evidence-based practices, most would agree that educational practices should be informed by research. So the question is how to use research to inform educational practice.

2. The term line of research inquiry connotes building a body of knowledge from study to study. Researchers always begin a new investigation by reviewing the prior research on the topic to situate a new study within a context of what is already known to move knowledge about the topic forward. The term also implies that knowledge derived from research proceeds from observing and describing phenomena, to uncovering the links between phenomena, to influencing phenomena to generate particular outcomes.

3. The principle of converging evidence has been proposed as a means for drawing on the findings from studies employing different designs to conclude whether a practice is researchbased. The import given to studies is ultimately in the hands of the professional, though many would put greatest weight on experimental studies in any mix of converging evidence as these designs are the only ones that can offer claims of causality. As Stanovich and Stanovich (2003) noted,

Issues are most often decided when the community of scientists gradually begins to agree that the preponderance of evidence supports one alternative theory rather than another

... The idea of converging evidence tells us to examine the pattern of flaws running through the research literature because the nature of this pattern can either support or undermine the conclusions that we might draw. (p. 16)

We then reviewed four potential protocols for identifying evidence-based practices. One is the IES and NSF's pipeline of evidence guidelines (IES \& NSF; 2013); the second is the new drug development process established by the U.S. Food and Drug Administration (2015), which is considered to be the gold standard of research protocols; the third is the National Institutes of Health's (2007) guidelines for the conduct of research; and the fourth emerged from our research into the major methodological designs used in literacy and special education research from which we developed a logical and iterative connection between research designs (Schirmer, Lockman, \& Schirmer, 2013, 2015; Schirmer, Schirmer, \& Lockman, 2008). We used the IES/NSF pipeline of evidence guidelines as a template on which to overlay the other three to determine if one protocol emerges. Table 1 provides a summary of the comparison between each of these. 
Table 1: Comparison of Line of Research Protocols

\begin{tabular}{|c|c|c|c|}
\hline $\begin{array}{l}\text { IES/NSF Pipeline of } \\
\text { Evidence }\end{array}$ & $\begin{array}{c}\text { Major Methodological Designs } \\
\text { Line of Research Protocol } \\
\text { (Authors) }\end{array}$ & $\begin{array}{l}\text { New Drug Development and } \\
\text { Review Process (U.S. Food } \\
\text { and Drug Administration) }\end{array}$ & $\begin{array}{c}\text { NIH Guidelines for } \\
\text { the Conduct of } \\
\text { Research }\end{array}$ \\
\hline $\begin{array}{l}\text { Foundational research: to } \\
\text { develop/refine theory and } \\
\text { examine phenomena }\end{array}$ & $\begin{array}{l}\text { Exploratory (qualitative } \\
\text { studies) and descriptive } \\
\text { research designs (survey, } \\
\text { comparison, synthetic } \\
\text { literature reviews, meta- } \\
\text { analyses, and qualitative } \\
\text { studies) to identify and } \\
\text { describe key variables }\end{array}$ & $\begin{array}{l}\text { Discovery and development } \\
\text { of new drugs }\end{array}$ & $\begin{array}{l}\text { Focus is on the } \\
\text { responsible use of } \\
\text { scientific } \\
\text { methodologies and } \\
\text { does not address } \\
\text { particular } \\
\text { methodological } \\
\text { designs }\end{array}$ \\
\hline $\begin{array}{l}\text { Early stage or exploratory } \\
\text { research: to examine the } \\
\text { connections or relationships } \\
\text { among constructs }\end{array}$ & $\begin{array}{l}\text { Predictive (correlational and } \\
\text { causal-comparative studies) to } \\
\text { determine the relationship } \\
\text { between variables }\end{array}$ & $\begin{array}{l}\text { Preclinical research: testing } \\
\text { on nonhumans to determine } \\
\text { the likelihood of safety and } \\
\text { effectiveness }\end{array}$ & \\
\hline $\begin{array}{l}\text { Design and development } \\
\text { research: to draw on theory } \\
\text { and evidence from } \\
\text { exploratory research to } \\
\text { design and test individual } \\
\text { components of an } \\
\text { intervention }\end{array}$ & $\begin{array}{l}\text { Explanatory (group } \\
\text { experimental and single } \\
\text { subject experimental studies) } \\
\text { to determine if one variable } \\
\text { (independent variable) will } \\
\text { cause a change in another } \\
\text { variable (dependent variable) }\end{array}$ & $\begin{array}{l}\text { Clinical research Phase 1: } \\
\text { testing for several months } \\
\text { on a small group (up to 100) } \\
\text { of healthy volunteers or } \\
\text { individuals with the disease } \\
\text { or condition to determine } \\
\text { safety and dosage }\end{array}$ & \\
\hline $\begin{array}{l}\text { Efficacy research: to test an } \\
\text { intervention under ideal } \\
\text { circumstances }\end{array}$ & $\begin{array}{l}\text { Explanatory (group } \\
\text { experimental and single } \\
\text { subject experimental studies) } \\
\text { to determine if a strategy is } \\
\text { effective when implemented in } \\
\text { a highly controlled or clinical } \\
\text { setting }\end{array}$ & $\begin{array}{l}\text { Clinical research Phase } 2 \text { : } \\
\text { testing for up to } 2 \text { years on a } \\
\text { larger group (up to several } \\
\text { hundred) of individuals with } \\
\text { the disease or condition to } \\
\text { determine efficacy and side } \\
\text { effects }\end{array}$ & \\
\hline $\begin{array}{l}\text { Effectiveness research: to } \\
\text { test an intervention under } \\
\text { typical circumstances }\end{array}$ & $\begin{array}{l}\text { Explanatory (group } \\
\text { experimental and single } \\
\text { subject experimental studies) } \\
\text { to determine if a strategy is } \\
\text { effective when implemented in } \\
\text { a realistic setting, such as an } \\
\text { actual classroom }\end{array}$ & $\begin{array}{l}\text { Clinical research Phase } 3 \text { : } \\
\text { testing for up to } 4 \text { years on a } \\
\text { large number (up to } 3,000 \text { ) } \\
\text { of individuals with the with } \\
\text { the disease or condition to } \\
\text { determine efficacy and } \\
\text { monitoring of adverse } \\
\text { reactions }\end{array}$ & \\
\hline $\begin{array}{l}\text { Scale-up research: to test an } \\
\text { intervention under typical } \\
\text { circumstances in a wide } \\
\text { range of contexts and } \\
\text { populations }\end{array}$ & $\begin{array}{l}\text { Explanatory (group } \\
\text { experimental studies) to } \\
\text { determine if a strategy is } \\
\text { effective when implemented in } \\
\text { a wide range of realistic } \\
\text { settings, such as several } \\
\text { schools or districts. }\end{array}$ & $\begin{array}{l}\text { Clinical research Phase } 4 \text { : } \\
\text { testing on several thousand } \\
\text { individuals with the disease } \\
\text { or condition to determine } \\
\text { safety and efficacy. }\end{array}$ & \\
\hline
\end{tabular}

Note. IES = Institute of Education Sciences; NSF = National Science Foundation; NIH = National Institutes of Health. 


\section{Warrants for Point of View}

IES/NSF includes six types of research that form their pipeline of evidence.

- Research Type 1 is foundational research. These studies are described by IES/NSF as providing foundational knowledge of teaching and learning, developing, and refining theory and examining phenomena in the absence of a direct link to educational outcomes.

- Research Type 2 is early stage or exploratory research. These studies examine the connections or relationships among constructs that may result in the development of a new intervention.

- Research Type 3 is design and development research. These studies draw on theory and empirical evidence in designing an intervention and testing individual components.

- Research Type 4 is efficacy research. These studies test the intervention under ideal circumstances.

- Research Type 5 is effectiveness research. These studies test the intervention under typical circumstances.

- Research Type 6 is scale-up research. These studies test the intervention under typical circumstances but in a wide range of contexts and populations.

\section{Foundational Research}

The IES/NSF foundational research step is consistent with the exploratory research and descriptive research designs that we found are commonly used to categorize two of the major types of educational research in the methodology literature.

Exploratory research is designed to develop insights, ideas, and understandings about a phenomenon. The phenomena are not well understood, variables need to be identified or discovered, or the purpose is to generate hypotheses for further investigation. Exploratory methodological designs are typically qualitative studies.

Descriptive research is designed to describe the characteristics of a phenomenon, differentiate a phenomenon from other phenomena, describe the variables, and document features of the phenomenon such as behaviors, events, process, attitudes, and beliefs. Descriptive methodological designs are typically survey studies, comparison studies, synthetic literature reviews, meta-analyses, and qualitative studies.

The IES/NSF foundational research step is also consonant with the discovery and development stage of the new drug development process, which is the stage in which researchers seek new insights into a disease or condition, develop new technologies, identify unanticipated effects of already approved treatments, and test promising molecular compounds.

\section{Early Stage or Exploratory Research}

The IES/NSF early stage or exploratory research step is consonant with what we found is typically referred to as Predictive designs in educational research. Predictive research is designed to identify the relationship between variables to predict a phenomenon. The variables have previously 
been identified and described and are now examined in terms of their relationship to one another to speculate about one variable influencing the occurrence of others. Predictive methodological designs are typically correlational studies and causal-comparative studies.

It is at this IES/NSF early stage or exploratory research stage that there is a parallel with the preclinical research stage of the new drug development process. This stage involves testing the drug in vivo, outside a living organism, and in vitro (inside a nonhuman living organism) to establish toxicity and dosing levels so that it can be determined whether the drug could cause serious harm.

\section{Design and Development Research}

The IES/NSF design and development research step is compatible with what we found are explanatory designs in educational research. Explanatory research is designed to identify the existence of a cause-effect relationship between variables. A previously found relationship between variables indicates the likelihood that one causes the other and investigating the likelihood confirms or disconfirms the direction and magnitude of the relationship. Explanatory methodological designs fall into two categories-experimental group designs and experimental single subject designs. Experimental group designs are typically random control trial, quasiexperimental, and single-group studies. Experimental single subject designs are typically simple time series, reversal, multiple baseline, changing criterion, and multiple treatment studies.

The clinical research stage of the new drug development process incorporates four phases that are quite similar to the IES/NSF protocol and the purpose of the first phase is similar to the IES/NSF design and development step. That is, in Phase 1, the drug is tested on a relatively small number of 20 to 100 healthy volunteers or individuals with the disease or condition over a period of several months for the purpose of determining safety and dosage.

\section{Efficacy Research}

Group and single-subject experimental research designs are also employed for what IES/NSF refers to as efficacy research. These studies are designed to determine if an instructional strategy is effective when it is implemented in a highly controlled or clinical setting by individuals who are trained to carry out the strategy and monitored to ensure they are implementing it with fidelity.

Phase 2 of the new drug development process corresponds to this efficacy research step. Studies in Phase 2 are conducted with up to several hundred individuals who have the disease or condition over a period of several months to 2 years for the purpose of determining the efficacy and side effects of the drug.

\section{Effectiveness Research}

Group and single subject experimental research designs are also used for effectiveness research but, unlike efficacy research, these studies are designed to determine if an instructional strategy is effective when it is implemented in a realistic setting by individuals who would normally be carrying out instruction in the setting. Actual classrooms are the typical setting for these studies and the instructional intervention is implemented by the teachers.

The third phase of the new drug development process is comparable to this step of the IES/NSF protocol. In this phase, the drug is tested with 300 to 3,000 individuals with the disease or condition over a period of 1 to 4 years for the purpose of assessing efficacy and adverse reactions. 


\section{Scale-Up Research}

Given that scale-up research involves evaluating the effectiveness of an instructional intervention in a wide range of typical contexts and populations, scale-up research is almost exclusively the domain of group experimental studies that can involve large numbers of participants across a variety of schools, districts, and even geographic areas. Scale-up research is quite similar to Phase 4 of the new drug development process in which the drug is tested on several thousand individuals with the disease or condition for the purpose of assessing safety and efficacy.

The fourth potential protocol we examined, the NIH guidelines, focuses on the responsible use of scientific methodologies in seeking new knowledge and encompasses the responsibilities of research supervisors and trainees, acquisition and maintenance of data, role of publication, establishment of authorship, function of peer review, importance of collaboration, disclosure of financial conflicts of interest, and protection of human subjects. While a critical part of the research process, the NIH guidelines do not contribute to understanding how particular designs can be employed to establish a line of research protocol that leads to the identification of evidence-based practices.

\section{Results and Substantiated Conclusions}

We conducted this conceptual study to determine if the IES/NSF pipeline of evidence guidelines could be applied as a protocol that researchers could follow in establishing evidence of effective instructional practices. To do this, we compared the IES/NSF guidelines, new drug development process, and our own research on major methodological designs and found that they show remarkable consistency in the process by which types of studies intended to answer different research questions build a body of evidence for practice, whether that practice is in the instructional environment or health care environment.

What our examination does not provide is the constellation of studies at each step in the IES/NSF pipeline process that warrant movement to the next step and the indicators of quality for each type of study to ensure that results are trustworthy and, thus, able to contribute to the pipeline of evidence. Without such assurance about trustworthiness of findings, practitioners are unlikely to embrace practices with research support any more than approaches with little or no evidence of effectiveness that are promoted in the media.

Clearly, no design is immune to flaws. Indeed, a key reason why research has shown that practitioners pay little attention to the published research is based in part on claims for significant findings and generalization of results that are often unwarranted given the limitations of the studies (Fusarelli, 2008; Goldhaber \& Brewer, 2008). Other reasons for the research-to-practice gap include limited accessibility to research reports, limited comprehensibility of research articles, limited relevance of research to actual practice, and little agreement among researchers about what constitutes evidence for claims of effective practice (Springer, 2010; Vaughn, Klingner, \& Hughes, 2000). Thus, it is crucial that in addition to making the case that a practice is research-based because evidence has been built from conceptual and descriptive studies to correlational and causal studies but also because there are a sufficient number of high quality studies at each step in the process. 


\section{Significance for Social Change}

Examination of the IES/NSF pipeline of evidence guidelines, the new drug development and review process established by the U.S. Food and Drug Administration, and the respective role of methodological designs found in the educational methodology literature indicate an emerging protocol that may lead to consensus about the identification of evidence-based practices. The process begins with studies that explore and describe phenomena pertinent to the learner and learning environment. As theory is built and key variables are identified, the process moves to studies that seek relationships among these variables. Having identified strong relationships, the process can move to establishing cause-effect claims through experimental designs. The approaches we examined align in recognizing that this is not a linear process but iterative as new questions sometimes lead back to previous designs. In this proposed protocol, identification of evidence-based practices must culminate in experimental studies that can reveal causality between instructional interventions and learning outcomes. However, the process cannot begin with experimental studies, for each design serves a crucial role in a line of research inquiry that can ultimately provide converging evidence for instructional practices. The next step is to determine the constellation of quantity and quality of studies needed to provide evidence that an instructional strategy has sufficient evidence of effectiveness.

Several cautions are warranted when discussing evidence-based practices. Cook and Odom (2013) suggested that there are three key issues:

1. No practice works for every student. Though an instructional strategy may work for most students with certain learning characteristics taught by teachers who are skilled in delivering the instruction, it will undoubtedly not work with every student with the same characteristics and teachers.

2. Insufficient high-quality research examining lines of research on instructional practices is available from which evidence-based practices can be identified. When the research base in insufficient, it is clear that teachers must and do make judgments about which practices are promising. The goal is to encourage researchers to conduct high-quality studies that build a base of evidence for instructional practices.

3. The research-to-practice gap is in part due to the difficulty of implementing and sustaining a new practice in the real world of classrooms and schools. No matter how well researched a practice is, and how clear findings have been about the characteristics of students who benefit and instructional conditions needed to achieve the outcomes attained in empirical studies, when applied in the messy world of real classrooms, problems and issues will undoubtedly arise. Willingness to problem-solve the issues that occur depends on the resilience and self-efficacy of those implementing the practice. 
Certainly, identifying evidence-based practices is not the only reason for carrying out educational research. However, it seems undeniable that instruction should be informed by research just as health care should be. Thus, the goal is to conduct high quality research that provides educators with confidence that the instructional practices they employ have a high likelihood of success and will enable a positive impact on the student's learning and, in the broader context, social change in the schools and each student's ability to contribute to society.

\section{References}

American Association of Colleges for Teacher Education. (2006). Research guidelines for schools, colleges, and departments of teacher education. Washington, DC: Author.

American Educational Research Association. (2006). Standards for reporting on empirical social science research in AERA publications. Educational Researcher, 35, 33-40. doi: $10.3102 / 0013189 x 035006033$

Cook, B. G., \& Odom, S. L. (2013). Evidence-base practices and implementation science in special education. Exceptional Children, 79, 135-144.

Cooper, H. (2010). Research synthesis and mea-analysis: A step-by-step approach (4th ed.). Los Angeles, CA: Sage.

Council for Exceptional Children. (2005). Special issues: Criteria for evidence-based practice in special education. Exceptional Children, 75, 135-207.

Council for Exceptional Children. (2014). Council for Exceptional Children: Standards for evidencebased practices in special education. Teaching Exceptional Children, 46, 206-212. doi:10.1177/0040059914531389

Dewey, J. (1937). Education and social change. Bulletin of the American Association of University Professors, 23, 472-474.

Division 16 of the American Psychological Association and Society for the Study of School Psychology Task Force on Evidence-Based Interventions in School Psychology. (2003). Procedural and coding manual for review of evidence-based interventions. Washington, DC: APA.

Fusarelli, L. D. (2008). Flying (partially) blind: School leaders' use of research in decision making. In F. M. Hess (Ed.), When research matters: How scholarship influences education policy (pp. 177-196). Cambridge, MA: Harvard Education Press.

Gersten, R., Fuchs, L., Compton, D., Coyne, M., Greenwood, C., \& Innocenti, M. S. (2005). Quality indicators for group experimental and quasi-experimental research in special education. Exceptional Children, 71, 149-164.

Goldhaber, D. D., \& Brewer, D. J. (2008). What gets studied and why: Examining the incentives that drive education research. In F. M. Hess (Ed.), When research matters: How scholarship influences education policy (pp. 197-217). Cambridge, MA: Harvard Education Press.

Institute of Education Sciences (IES) \& National Science Foundation (NSF). (2013). Common guidelines for education research and development. Washington, DC: Authors.

Kazdin, A. E. (2011). Single-case research design: Methods for clinical and applied settings (2nd ed.). New York, NY: Oxford University Press.

National Institutes of Health. (2007). Guidelines for the conduct of research in the intramural research program at NIH. Bethesda, MD: Author. 
Schirmer, B. R., Lockman, A. S., \& Lockman, T. N. (2013, May). Protocol for lines of research inquiry leading to evidence-based practices. Paper presented at the Annual Conference of the Association for Behavior Analysis International, Minneapolis, MN.

Schirmer, B. R.., Lockman, A. S., \& Lockman, T. N. (2015, May). Tackling the evidence-based practice issue: Do the IES/NSF guidelines provide a line-of-research protocol? Paper presented at the Annual Conference of the Association for Behavior Analysis International, San Antonio, TX.

Schirmer, B. R., Schirmer, T. N., \& Lockman, A. S. (2008, September). Connection between methodological designs and evidence for practice. Paper presented at the First Education Conference of the Association for Behavior Analysis International, Reston, VA.

Springer, K. (2010). Educational research: A contextual approach. Hoboken, NJ: Wiley.

Stanovich, P. J., \& Stanovich, K. E. (2003). Using research and reason in education: How teachers can use scientifically based research to make curricular and instructional decisions. Washington, DC: National Institute for Literacy, National Institute of Child Health and Human Development, U.S. Department of Education, U.S. Department of Health and Human Services.

U. S. Food and Drug Administration. (2015). The drug development process. Retrieved from http://www.fda.gov/ForPatients/Approvals/Drugs/default.htm

Vaughn, S., Klingner, J., \& Hughes, M. (2000). Sustainability of research-based practices. Exceptional Children, 66, 163-171.

What Works Clearinghouse. (2010). Evidence standards for reviewing studies. Retrieved from http://ies.ed.gov/ncee/wwc/references/iDoc Viewer/Doc.aspx?docId=20\&tocId=1

The Journal of Educational Research and Practice provides a forum for studies and dial ogue that allows readers to better develop social change in the field of education and learning. Journal content may focus on educational issues of all ages and in all settings. It also presents peer-reviewed commentaries, book reviews, interviews of prominent individuals, and additional content. The objectives: We publish research and related content that examines current relevant educational issues and processes aimed at presenting readers with knowledge and showing how that knowledge can be used to impact social change in educational or learning environments. Additional content provides an opportunity for scholarly and professional dial ogue regarding that content's usefulness in expanding the body of scholarly knowledge and increasing readers' effectiveness as educators. The journal also focuses on facilitating the activities of both researcher-practitioners and practitioner-researchers, providing optimal opportunities for interdisciplinary and collaborative thought through blogging and other communications.

Walden University Publishing: http://www.publishing.waldenu.edu 